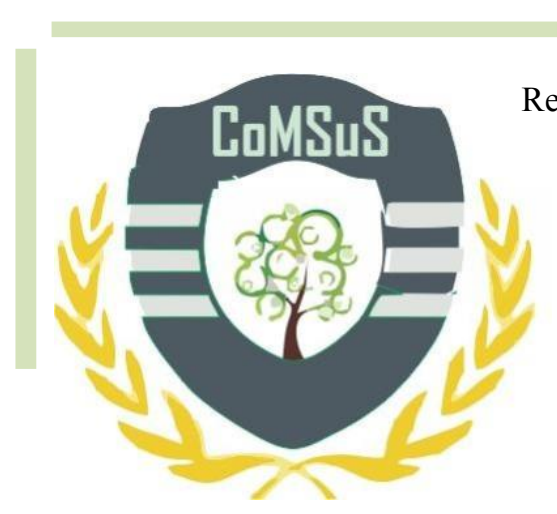

Recebido em 17/07/2018. Aprovado em 03/12/2018. Publicado em 28/02/2019.

Editor: Dr. Ivano Ribeiro

Processo de Avaliação: Double Blind Review - SEER/OJS

e-ISSN: $2359-5876$

DOI: $\underline{10.5935 / 2359-5876.20180006}$

\title{
A INFLUÊNCIA DE FATORES SOCIOECONÔMICOS NA DETERMINAÇÃO DO PERFIL DE RISCO DE ALUNOS UNIVERSITÁRIOS
}

\section{THE INFLUENCE SOCIOECONOMIC FACTORS IN DETERMINING THE RISK PROFILE OF UNIVERSITY STUDENTS}

\section{RESUMO}

\author{
Silvio Roberto Stefano ${ }^{1}$ \\ Eduardo Christ ${ }^{2}$ \\ Léo Raifur ${ }^{3}$
}

O estudo das finanças comportamentais vem ocupando espaço na área de finanças e, ao mesmo tempo, ensejando e estimulando trabalhos acadêmicos com vistas à explorar e desenvolver esta área de estudo. O objetivo principal deste trabalho consiste na análise da influência dos fatores socioeconômicos dos estudantes de Graduação de Administração na Mesorregião do Centro-Sul do Paraná na determinação do perfil de risco. O estudo caracteriza-se como exploratório, ex post facto, dimensão temporal transversal e escopo quantitativo. Os dados foram coletados dados por meio de questionário estruturado aplicado à uma amostra de 309 estudantes, em um universo de 648. O estudo testou a influência de três aspectos socioeconômicos: gênero, idade e renda - que consistiram as hipóteses da pesquisa. Concluiuse que o gênero e a idade são aspectos determinantes do perfil de risco, evidenciando-se que os homens são mais propensos ao risco que as mulheres e que, à medida que aumenta a idade do indivíduo, diminui a propensão ao risco. A renda não se mostrou significativa.

Palavras-chave: Finanças Comportamentais; Perfil de Risco; Fatores Socioeconômicos.

\begin{abstract}
This paper of behavioral finances has been occupying space in finance and, at the same time, providing and stimulating academic work in order to explore and develop this area. The objective this paper to analyze the influence of socioeconomic factors of undergraduate students in the Mid-South Meso region of Paraná in the determination the risk profile. The study is characterized as exploratory, ex post facto, transverse temporal dimension and quantitative scope. Data were collected using a structured questionnaire applied to a sample of 309 students in a universe of 648. The research tested the influence of three socioeconomic aspects: gender, age and income - which consisted of the hypothesis of the research. It was concluded that gender and age are determinant aspects of the risk profile, showing that men are more risk-prone than women and that, as the age of the individual increases, the risk propensity decreases. Income was not significant.
\end{abstract}

Keywords: Behavioral Finance; Risk Profile; Socioeconomic Factors.

${ }^{1}$ Pós-Doutor em Administração pela Univali. Doutor em Administração pela Universidade de São Paulo - USP. Professor do Programa de Pós-Graduação em Administração da Unicentro - PPGADM / UNICENTRO. E-mail: professor-silvio@hotmail.com (D) http://orcid.org/0000-0002-5871-8686

${ }^{2}$ Mestre em Administração pelo Programa de Pós-Graduação em Administração da Unicentro - PPGADM / UNICENTRO. E-mail: eduardo christ@hotmail.com

${ }^{3}$ Doutor em Administração pela FEA/USP. Professor Adjunto da Universidade Estadual do Centro-Oeste. Professor do Programa de Pós-Graduação em Administração da Unicentro - PPGADM / UNICENTRO. E-mail: raifur@yahoo.com.br 


\section{INTRODUÇÃO}

O comportamento humano tem sido foco de diversas pesquisas com o objetivo de auxiliar na compreensão desses aspectos comportamentais na sociedade e nas organizações. Diversas áreas de conhecimento estudam o comportamento das pessoas na esfera individual, grupal e organizacional, como, por exemplo, o comportamento organizacional em gestão de pessoas, o comportamento do consumidor em marketing $\mathrm{e}$ as finanças pessoais $\mathrm{e}$ comportamentais em administração financeira.

Barberis \& Thaler (2003) defendem que os mercados financeiros, por meio de modelos em que os agentes são "racionais", podem ter dois significados: primeiro, quando recebem novas informações, os agentes atualizam suas crenças corretamente e os agentes fazem escolhas que são normalmente aceitáveis, no sentido de que são consistentes com a teoria da utilidade esperada.

No entanto, Kahneman \& Tversky (1974) questionam o alcance da racionalidade, assim como a maximização da riqueza oriunda da teoria da utilidade. Os autores concluem que a forma como os argumentos são estruturados podem modificar a tomada de decisão do indivíduo. Utilizando-se de questões que se diferenciavam na forma de construção do argumento, sem, contudo, alterar os produtos resultantes desses argumentos, concluíram que as pessoas são avessas ao risco no domínio dos ganhos e propensas ao risco no domínio das perdas. Ao conjunto desses estudos atribuiu-se o nome de Teoria do Prospecto que, na literatura, é comumente difundida como finanças comportamentais.

Em tese, as evidências comportamentais de Kahneman \& Tversky (1974) que fundamentalmente desdobram-se em duas vertentes: vieses cognitivos e estrutura de argumentos, estabelecem que a propensão, do indivíduo, ao risco, quando está perdendo, associa-se mais à resistência em realizar perdas, do que, propriamente, mostrar-se propenso ao risco. Ou seja, a dor da perda é substancialmente maior do que a alegria do ganho.

Serpa (2012) destaca que o estudo das finanças comportamentais vem ocupando espaço na área de finanças e, ao mesmo tempo, ensejando e estimulando trabalhos acadêmicos com vistas à explorar e desenvolver esta área de estudo. Conceitos tradicionais de economia, sobre o homus economicus, têm sido questionados, ao se considerarem as evidências empíricas, demonstrando a presença de comportamentos viesados e racionalmente limitados geram um conjunto amplo de distorções e incompreensões, sobretudo no mercado de capitais. A esse contexto, Pimenta (2012) ainda acrescenta que as finanças comportamentais tentam identificar a forma pela qual as emoções e as falhas cognitivas podem influenciar o processo de decisão dos indivíduos.

Torralvo (2010) elenca que eventos recentes, no mercado financeiro, têm fornecido indícios de que os agentes econômicos nem sempre operam de forma inteiramente racional. Neste sentido, as acentuadas desvalorizações dos principais índices de ações em 2000 e em 2008 em diversos países do mundo foram atribuídas a correções de ativos que, após seguidas valorizações, passaram a refletir uma situação de geração de riqueza que não se verificava na realidade, em termos tangíveis.

Saurin et al (2015) analisaram o viés do "status quo" e perfil de risco em tomadas de decisões por estudantes de cursos de pós-graduação do Brasil e Portugal, onde os resultados apontaram que a presença do viés foi predominante, ou seja, os respondentes que haviam estudado finanças comportamentais optaram mais por opções alternativas do que os outros respondentes, onde enfatiza-se a importância de compreender a influência de vieses comportamentais nas tomadas de decisões, pois eles podem comprometer e ou influenciar 
decisões em uma organização.

A compreensão destes aspectos comportamentais revela-se, ao mesmo tempo, emergente latente, para a construção teórica na área de finanças, além de assumir estreita relação, além de administração de forma geral, mas também com a área de economia e psicologia. Assim, o objetivo principal desta pesquisa foi analisar a influência dos fatores socioeconômicos dos estudantes de graduação em administração na Mesorregião do Centro-Sul do Paraná na determinação do perfil de risco.

A presente pesquisa pretende contribuir para a compreensão das finanças comportamentais, analisando as diferenças entre públicos, gênero, renda e outros aspectos socioeconômicos influenciam no perfil de risco de indivíduos. O estudo está dividido em introdução, referencial teórico, metodologia de pesquisa, análise dos resultados e considerações finais.

\section{REFERENCIAL TEÓRICO 2.1 Finanças Comportamentais}

Segundo Fernandes (2012) os estudos sobre as Finanças Comportamentais tiveram início por meio de anomalias detectadas por estudiosos do mercado financeiro. Estas anomalias submetem ao conceito de que o ser humano é influenciado pelas emoções no processo de tomada de decisão. Logo, possui uma capacidade irracional de análise.

Para Rogers (2012) os estudos sobre as Finanças Comportamentais tiveram início por meio de anomalias detectadas por estudiosos do mercado financeiro. Estas anomalias submetem ao conceito de que o ser humano é influenciado pelas emoções no processo de tomada de decisão. Logo, possui uma capacidade irracional de análise.

Os conceitos da Moderna Teoria de Finanças em Leone (2011) estão alicerçados em premissas em que os agentes do mercado apresentam um comportamento humano racional (corroborado pela hipótese do mercado eficiente) e, por isso, tomam decisões que buscam maximizar seu bem-estar ao longo da curva de utilidade e formam expectativas não viesadas sobre eventos futuros. Estes conceitos norteiam o processo de tomada de decisões dos investidores financeiros, referente, essencialmente, à formação de carteiras de ativos, onde as variáveis risco e retorno são de fundamental importância.

De acordo com Rogers (2012) A teoria do prospecto, criada por Kahneman \& Tversky (1979), busca explicar os vieses cognitivos (heurísticos) no processo de tomada de decisão. Esses autores propõem uma nova teoria de utilidade esperada para tomada de decisão em condições de risco e buscam explicações para os processos pelos quais os impulsos sensoriais são transformados, reduzidos, elaborados, armazenados, recuperados e usados. A teoria do prospecto enumera que o processo de tomada de decisão não é estritamente racional, particularmente quando o tempo disponível é limitado, ao invés disto, os tomadores de decisão usam atalhos mentais no processo. Apresenta-se o Quadro 1 com os principais conceitos da teoria de finanças: 
Quadro 1. Principais conceitos da moderna Teoria de Finanças

\begin{tabular}{|c|c|}
\hline $\begin{array}{l}\text { Teoria da Utilidade } \\
\text { Esperada (TUE) }\end{array}$ & $\begin{array}{l}\text { Bernoulli }(1738,1954) \text { estabelece que o investidor é racional e avalia o risco em } \\
\text { função do impacto deste sobre seu nível de riqueza. O investidor conhece e organiza } \\
\text { de forma lógica suas predileções, buscando maximizar a "utilidade" de suas escolhas, } \\
\text { atribuindo assim, com exatidão, probabilidades aos eventos futuros quando estes } \\
\text { estiverem subordinados a escolhas que envolvam incertezas e risco. }\end{array}$ \\
\hline Teoria do prospecto. & $\begin{array}{l}\text { De acordo a forma com que a situação é apresentada ao tomador de decisão pode } \\
\text { influenciar no seu processo decisório, levando-o a decisões contraditórias em } \\
\text { situações em que a posição final dos bens seria equivalente (Kahneman \& Tversky, } \\
\text { 1974) }\end{array}$ \\
\hline $\begin{array}{l}\text { Teoria de } \\
\text { Portfólio } \\
\text { Markowitz }\end{array}$ & $\begin{array}{l}\text { Na moderna teoria do portfólio, o retorno esperado de um investimento é a média } \\
\text { aritmética ponderada esperada de todos os retornos que compõem a carteira. E o risco } \\
\text { da carteira pode ser representado pela dispersão de seus retornos em relação ao seu } \\
\text { retorno esperado (Markowitz, 1959) }\end{array}$ \\
\hline $\begin{array}{l}\text { A Hipótese de } \\
\text { Eficiência } \\
\text { de Mercados de } \\
\text { Capitais }\end{array}$ & $\begin{array}{l}\text { A HEM (Fama, 1970) tem sido a hipótese central na área de finanças há quase } 40 \\
\text { anos. Fundamenta-se na teoria da utilidade esperada e nas expectativas racionais. } \\
\text { Essas duas proposições combinadas afirmam que os indivíduos/investidores são } \\
\text { considerados racionais, conhecem e ordenam de forma lógica suas preferências e } \\
\text { buscam maximizar a "utilidade" de suas escolhas. }\end{array}$ \\
\hline $\begin{array}{l}\text { Modelo de } \\
\text { Precificação } \\
\text { de Ativos de Capital - } \\
\text { CAPM }\end{array}$ & $\begin{array}{l}\text { Proposta por Sharpe (1964), esta teoria baseia-se na maneira pela qual as ações são } \\
\text { precificadas tomando por base sua particularidade de risco, incorporando o prêmio } \\
\text { pelo risco de mercado e o retorno livre de risco. }\end{array}$ \\
\hline
\end{tabular}

Fonte: Pimenta (2012) adaptado pelos autores.

O Quadro 1 apresenta as principais teorias modernas de finanças comportamentais e sua síntese, desde a teoria da utilidade esperada que propõe que os agentes econômicos são totalmente racionais e tomam decisões com padrão definido por outro lado a teoria do prospecto que também está apresentada no quadro propõe que os agentes tomam decisões irracionais ou subjetivas baseadas em percepções conhecimento empírico dependendo da perspectiva.

Segundo Leone (2011), as Finanças Comportamentais têm como principal objetivo identificar e compreender os frames, ilusões cognitivas que fazem com que pessoas cometam erros sistemáticos de avaliação de valores, probabilidades e riscos. Neste sentido, os processos heurísticos, portanto, podem resultar em decisões errôneas. Alguns exemplos característicos de ilusões que resultam do uso de processos heurísticos e/ou enviesados são: Autoconfiança Excessiva e Otimismo; Padrões Históricos; Aposta Errônea; Ponderação Contabilidade Mental; Tendência ao Exagero e o Efeito Manada.

As Finanças Comportamentais segundo Pimenta (2012) não visam substituir as teorias existentes, mas sim servir-lhes de complemento a partir da proposição de aspectos comportamentais para o entendimento do processo decisório dos agentes de mercado. Esse campo de estudo postula que alguns fenômenos financeiros são mais bem entendidos com o uso de modelos em que os agentes não são considerados completamente racionais, e seus estudos têm se concentrado na compreensão das ilusões cognitivas e de suas implicações no comportamento dos tomadores de decisão

Mendes (2009) afirma que a partir da ideia de que as pessoas perseguem a maximização de seu bem-estar, o senso de controle constitui tema relevante para melhor entender como as pessoas podem decidir sobre temas que afetam ou afetarão a manutenção de seu estilo de vida, destacadamente itens relacionados a investimentos pessoais, como é o caso da constituição de aposentadoria. Ademais, na ausência do senso de controle, as pessoas tendem a sentir-se inseguras, possibilitando o desencadeamento de efeitos sobre seu desempenho, no exercício de 
papéis na sociedade, na convivência familiar, ou mesmo no desenvolvimento de suas atividades profissionais.

Ainda para Pereira (2011), os vieses financeiros incluem: irrealistas opiniões positivas sobre si mesmo, o otimismo irrealista, ilusão de controle, atribuições de interesse próprio, ilusões positivas em um grupo ou em evitar a sociedade, pesar egocentrismo. Todos estes não derivam das heurísticas utilizadas, mas de distorções na forma como as pessoas interpretam problemas e como eles lidam com o risco de cheias de situações de incerteza.

Segundo Ritter (2003, p. 430) Finanças comportamentais utiliza o modelo onde alguns agentes não são totalmente racionais devido suas preferências, crenças ou aversão a perda. Um exemplo da hipótese sobre as preferências é que as pessoas são avessas a perda, um ganho de US \$2 deveria fazer as pessoas se sentirem melhor, tanto quanto a perda de um dólar faz sentir pior.

\subsection{Teoria do Prospecto}

De acordo com Tversky \& Kahneman (1974) muitas decisões apoiam-se em crenças baseadas na probabilidade de eventos como: o resultado de uma eleição, a culpa de um réu, ou o preço futuro do dólar. Essas crenças são geralmente expressas em frases como "eu acho que", "as chances são", "é improvável que". As pessoas confiam em um alguns princípios heurísticos que reduzem as tarefas complexas de avaliar probabilidades.

Para Torralvo (2010) esses elementos podem ser traduzidos pela facilidade com que ideias vem a mente (disponibilidade), a influência de eventos passados no processo decisório (representatividade) e a existência de um referencial capaz de impactar a tomada de decisão (ancoragem). O uso sistemático dessas heurísticas conduz a uma tendência de avaliação de forma parcial das perspectivas futuras envolvendo incerteza e risco, denominados de efeitos Certeza, Reflexão e Isolamento, que, por sua vez, também influenciam o processo decisório, culminando na Teoria do prospecto.

Por meio dessa teoria, Kahneman \& Tversky (1979) fazem uma crítica ao modelo de decisão baseado no risco, descrevendo um modelo alternativo. A tomada de decisão sobre a perspectiva de risco apresenta vários efeitos persuasivos que são incompatíveis com os princípios básicos da teoria da utilidade.

Contrariando pressupostos econômicos que estimulam investidores à arriscar quando estão ganhando e serem avessos ao risco quando estão perdendo, as Finanças Comportamentais dão destaque à "aversão às perdas", e não "aversão ao risco", ou seja, as pessoas preferem não sofrer a dor da perda do que o prazer de um ganho equivalente. Também assumem riscos quando estão perdendo, mas são totalmente avessos ao risco quando estão ganhando.

Na Teoria do Prospecto, Kahneman \& Tversky (1974) propõem uma curva de valor, em que as propriedades essenciais são: 1) a função de valor não está relacionada com a riqueza; 2) a função valor é normalmente côncava acima do ponto de referência e convexa abaixo desse ponto; 3) a curva de valor é mais inclinada no domínio das perdas do que no domínio dos ganhos.

Para Pimenta (2012), a teoria do prospecto sugere a hipótese segundo a qual os investidores possuem uma disposição de vender ações vencedoras, com lucro em relação ao preço de compra, e de manter ações perdedoras, com perda em relação ao preço de compra (Shefrin \& Statman, 1985).

A aversão à perda para Kahneman \& Taversky (1991) implica em um maior impacto na curva, produzindo uma diferença maior com relação a curva de ganhos. Uma dimensão é geralmente maior quando a diferença de que é avaliada como uma perda do que quando a 
mesma diferença é avaliado como um ganho. Diminuindo a sensibilidade implica que o impacto de uma diferença é atenuada quando ambas as opções são afastadas do ponto de referência para a dimensão relevante. Esses esquemas simples podem estar sujeitos a interpretações alternativas.

Segundo Pimenta (2012) enquanto a teoria moderna de finanças baseia se na busca da maximização da utilidade esperada, as Finanças Comportamentais estabelecem que algumas variáveis econômicas não podem ser descritas pelas condições de equilíbrio da teoria moderna, tendo em vista que os agentes financeiros tomam decisões muitas vezes incompatíveis com atitudes baseadas em expectativas racionais (Kimura, 2003).

A combinação de finanças e outras ciências sociais, de acordo com Shiller (2003) se tornou conhecida como finanças comportamentais e levou a um profundo aumento de nosso conhecimento dos mercados financeiros. Ao julgar o impacto do comportamento, é importante aplicar as normas adequadas. Claro, nós não esperamos que está pesquisa nos forneça um método para ganhar muito dinheiro através do aproveitando a ineficiência dos mercados. Isto não torna a teoria da eficiência dos mercados correta.

Segundo Barberis \& Thaler (2003) a teoria do prospecto argumenta que ao escolher entre apostas, as pessoas calculam os ganhos e perdas de cada um e escolhe, aquele com a maior utilidade potencial em um contexto financeiro, isto sugere que as pessoas podem escolhem seu portfólio de investimentos pelo cálculo de cada atribuição, os ganhos e perdas potenciais no valor de suas participações e em seguida, tomar a decisão em favor de que possui maior utilidade potencial Em outras palavras, eles escolhem, a fração da riqueza financeira em ações, para maximizar.

\section{METODOLOGIA}

Esta pesquisa é caracterizada como estudo exploratório de natureza não experimental (ex post facto), em que o pesquisador não manipula as variáveis com o interesse de observar seus efeitos. Na dimensão temporal é classificada como transversal (crosssection), em que cada indivíduo representa uma única observação na amostra, constituída durante o mês de novembro por meio de instrumento estruturado de coleta de dados. Em seu escopo, o estudo classifica-se como estatístico, com ênfase na amplitude (Cooper \& Schindler, 2003).

A amostra aleatória simples foi constituída por 310 alunos do curso de administração na Mesorregião do Centro-Sul do Paraná situada no interior do Estado do Paraná de um universo de 648 alunos matriculados.

O instrumento de coleta de dados foi baseado na obra "Teoria do Prospecto" (Kahnemann \& Tversky, 1979). Nessa obra os autores estabeleceram o marco seminal das pesquisas com foco nas finanças comportamentais. A teoria de Kahnemann \& Tversky pressupunha que o indivíduo apresenta comportamentos diferentes, quando se trata de risco, quando se trata de ambientes de ganho ou de perda. Utilizando questões, cujos argumentos foram estruturados em cenários (domínios) de ganho ou de perda, ou autores concluíram que os indivíduos tendem a ser mais agressivos (assumir mais riscos) no domínio das perdas, e mais conservadores no domínio dos ganhos.

Para consecução deste estudo foram utilizadas 15 questões, extraídas e adaptadas do estudo de Kahneman \& Tversky (1979), sendo que nove delas consistiam de argumentos associados ao domínio dos ganhos e, as outras seis, relacionavam-se ao domínio das perdas.

Tendo por base o objetivo de estabelecer o perfil de risco dos estudantes, testando-os com o seu perfil socioeconômico, foram definidas as seguintes hipóteses: 
$\mathbf{H}_{0,1}$. O gênero não é determinante do perfil do risco

$\mathbf{H}_{0,2}$. A idade não é determinante do perfil de risco

$\mathbf{H}_{\mathbf{0}, 3}$. A renda não é determinante do perfil de risco

O perfil de risco de cada respondente foi determinado pelo escore somado de cada uma das questões do questionário que possuía duas alternativas, sendo uma associada à aversão ao risco (a qual atribuiu-se o valor igual zero) e, outra, associada à propensão ao risco (a qual atribui-se o valor igual a um). Dessa forma, o perfil de risco possui valor igual a zero no perfil de máxima aversão ao risco e de 15 no perfil de máxima propensão ao risco. O perfil de risco pode ser descrito pelo modelo a seguir:

$$
\mathrm{PR}_{j}=\sum_{i=1}^{n} \mathrm{Q}_{i}
$$

Onde $\mathrm{PR}_{j}=$ Escore do perfil do risco do indivíduo $j ; Q_{i}=$ valor atribuído à $i$-ésima questão (assume valor 0 ou 1 ); $n=$ total de questões (15).

Para efeito de classificação do perfil de risco, a escala foi enquadrada em três níveis conforme Tabela 1.

Tabela 1. Perfil de risco

\begin{tabular}{c|c}
\hline Escore & Perfil de risco \\
\hline 0 a 5 & Conservador \\
\hline 6 a 10 & Intermediário \\
\hline 11 a 15 & Agressivo \\
\hline
\end{tabular}

\section{Estatísticas para Teste das Hipóteses}

Para testar $\mathrm{H}_{0,1}$ foi utilizado o teste t-Student para duas amostras independentes dado pelo modelo a seguir:

$$
T=\frac{\left(\overline{\mathrm{PR}}_{\mathrm{M}}-\overline{\mathrm{PR}}_{\mathrm{F}}\right)-\left(\mu_{\mathrm{M}}-\mu_{\mathrm{F}}\right)}{\hat{S} \sqrt{\overline{n_{\mathrm{M}}}+\overline{\boldsymbol{L}}_{\mathrm{F}}}}
$$

Onde: $T=$ Estatística t-Student; $P R=$ Valor médio do perfil de risco de cada gênero (assumiu-se que $\mu_{\mathrm{M}}-\mu_{\mathrm{F}}=0$ ); $S=$ desvio-padrão conjunto dos grupos.

Para que a hipótese nula seja rejeitada é necessário que $T$ seja diferente de 0 (zero) considerando um intervalo de confiança de $95 \%(p<0,05)$. 
Para testar $\mathrm{H}_{0,2}$ foi utilizado o coeficiente de correlação de Spearman ( $\left.\rho\right)$, dado por:

$$
\rho_{S}=\frac{\sum_{i=1}^{n}\left(r_{I i}-\bar{r}_{I}\right)\left(r_{P R i}-\bar{r}_{P R}\right)}{\sqrt{\sum_{i=1}^{n}\left(r_{I i}-\bar{r}_{I}\right)^{2} \sum_{i=1}^{n}\left(r_{P R i}-\bar{r}_{P R}\right)^{2}}}
$$

Onde: $r_{I}=$ ordem da $i$-ésima idade; $\overline{r_{I}}=$ ponto médio das ordens de idade; $r_{P R}=$ ordem do $i$-ésimo perfil de risco; $\bar{r}_{P R}=$ ponto médio das ordens do perfil de risco.

Para que a hipótese nula seja rejeitada é necessário que o coeficiente de correlação seja diferente de zero em um intervalo de confiança de $95 \%(\rho \neq 0 ; p<0,05)$.

Para testar $\mathrm{H}_{0,3}$ igualmente foi utilizado o coeficiente de correlação de Spearman.

\section{ANÁLISE DE DADOS E RESULTADOS}

A Mesorregião do Centro-Sul do Paraná envolve 29 municípios em três microrregiões (Guarapuava, Palmas e Pitanga) do Estado do Paraná. Possui uma população de mais de 500 mil habitantes. Os estudantes pesquisados são dessa mesorregião de uma Universidade Pública, com turmas em diversas cidades.

A Figura 1 descreve o perfil socioeconômico da amostra pesquisada. Observa-se que $53 \%$ dos respondentes são homens, enquanto $47 \%$ são mulheres. Trata-se de um público bastante jovem, com idade até 21 anos (52\%) e solteiros (75\%). Com relação à renda, $45 \%$ dos respondentes tem renda pessoal de até $\mathrm{R} \$ 1.000,00$, enquanto $30 \%$ disse possuir renda de até $\mathrm{R} \$$ 2.000. Ainda, 41\% dos estudantes estão matriculados no primeiro ano de curso, representando a maior fatia da amostra.

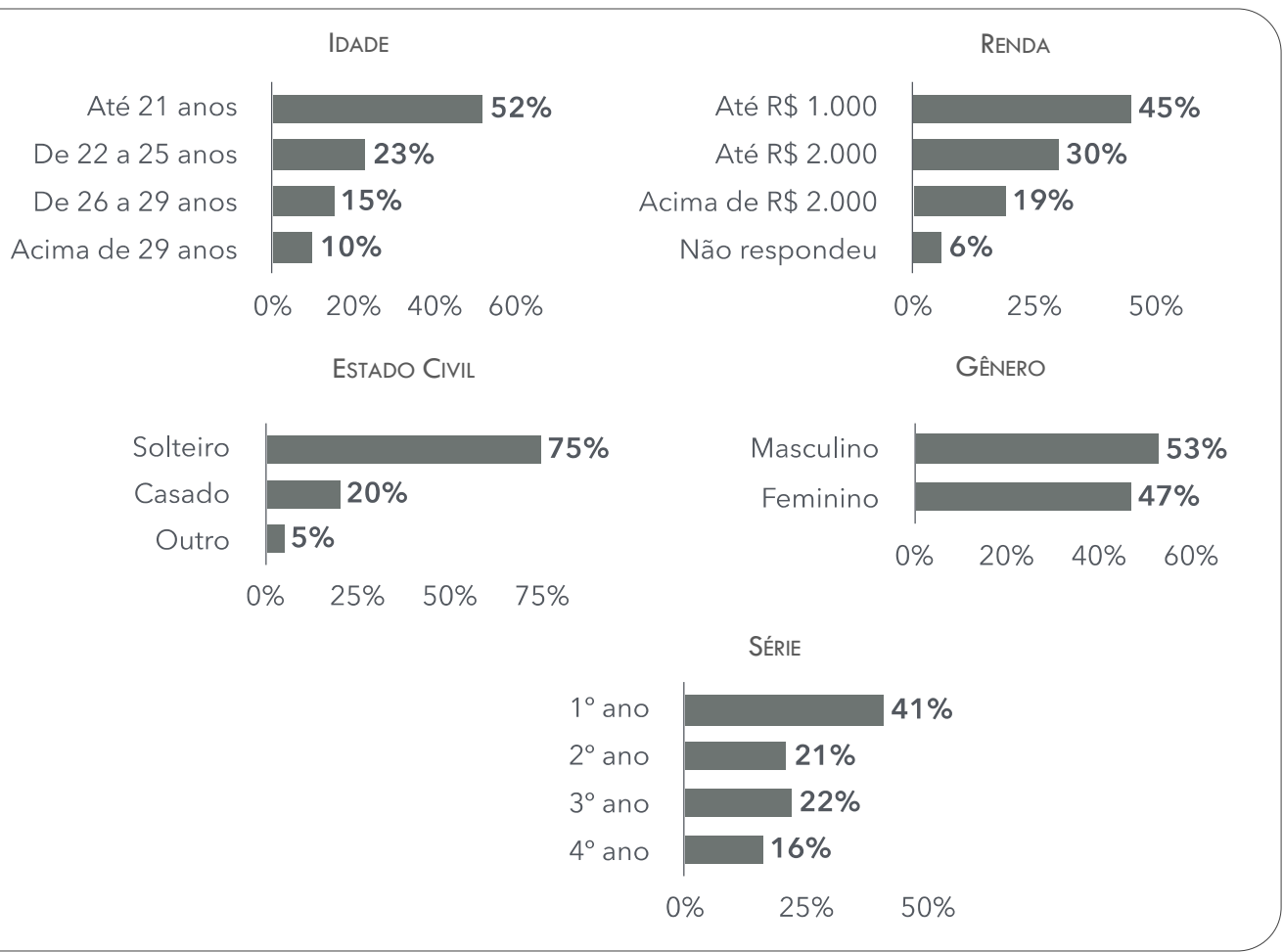

Figura 1. Infográfico - Perfil Socioeconômico 
Com relação a auto-avaliação sobre conhecimento financeiro, 45,3\% afirmaram terem bom conhecimento em finanças, enquanto $41,7 \%$ descreveram seu conhecimento como regular (Tabela 2).

Tabela 2. Conhecimento Financeiro

\begin{tabular}{ccr}
\hline $\begin{array}{c}\text { Conhecimentos } \\
\text { Financeiros }\end{array}$ & Frequência & \multicolumn{1}{c}{$\%$} \\
\hline Ótimo & 16 & $5,2 \%$ \\
Bom & 139 & $45,3 \%$ \\
Regular & 128 & $41,7 \%$ \\
Pouco & 24 & $7,8 \%$ \\
\hline
\end{tabular}

Com relação à investimentos ou aplicações da renda pessoal (Tabela 3), constatou-se que cerca de $35 \%$ dos respondentes não realizam nenhum tipo de investimento. Outros 35\% investem entre $1 \%$ a $10 \%$ da sua renda pessoal, enquanto $12,7 \%$ investem entre $10 \%$ a $20 \%$.

Tabela 3. Faixa da renda investida

\begin{tabular}{lcc}
\hline Renda Investida & Frequência & $\%$ \\
\hline De $1 \%$ a $10 \% ;$ & 108 & $35,18 \%$ \\
De $10 \%$ a $20 \%$ & 39 & $12,70 \%$ \\
De $20 \%$ a $30 \%$ & 29 & $9,45 \%$ \\
Mais de $30 \% ;$ & 25 & $8,14 \%$ \\
Não Investe & 109 & $34,53 \%$ \\
\hline
\end{tabular}

Com relação ao perfil de risco, observou-se que, predominantemente, a amostra possui perfil intermediário, com média 6,54 , mediana 6,00 e moda 7,0 . Pela mediana tem-se que $50 \%$ dos respondentes obtiveram escore igual ou menor que 6 , enquanto $50 \%$ obtiveram escore superior a 6 . Na Figura 2 verifica-se que a distribuição é ligeiramente assimétrica à direita (mediana $<$ média), porém com a moda no centro da distribuição.

\begin{tabular}{lr}
\hline \multicolumn{1}{c}{ Estatística } & Valor \\
\hline Média & 6,54 \\
Mediana & 6,00 \\
Moda & 7,00 \\
Desvio-Padrão & 3,01 \\
Mínimo & 0 \\
Máximo & 15 \\
\hline
\end{tabular}

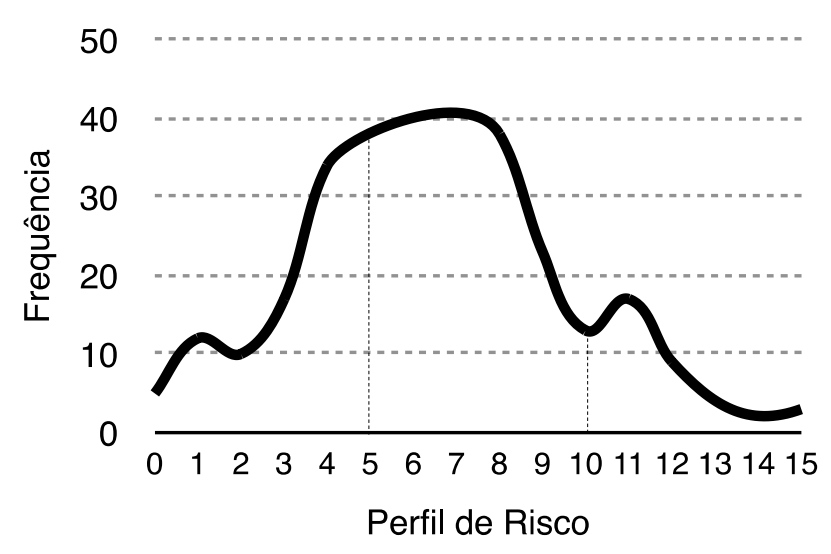

Figura 2. Perfil de Risco - Estatística Descritiva

Observando-se os critérios adotados para classificação de risco, tem-se que 51,6\% dos respondentes encontram-se no perfil de risco intermediário (escore de 6 a 10), enquanto 37,6\% 
mostraram-se conservadores (escore de 0 a 5). Apenas 11,3\% da amostra apresentaram perfil agressivo (Tabela 4).

Tabela 4. Classificação do Perfil de Risco

\begin{tabular}{ccc}
\hline Perfil de Risco & Frequência & $\%$ \\
\hline Conservador & 116 & $37,6 \%$ \\
Intermediário & 158 & $51,1 \%$ \\
Agressivo & 22 & $11,3 \%$ \\
\hline
\end{tabular}

Como defendido pela teoria, constatou-se que o perfil da amostra apresentou aversão ao risco. O conhecimento em finanças, ou a série de matrícula do estudante não afeta esse perfil.

\section{Teste de Hipóteses}

Teste de $\mathbf{H}_{0,1}$. O gênero não é determinante do perfil do risco

Nas Tabelas 5 e 6 é apresentada a estatística de teste para o perfil do risco em função do gênero. A média dos homens $(6,96)$ foi ligeiramente superior à das mulheres $(6,07)$. Em termos do questionário aplicado, tem-se que à diferença foi de uma resposta adicional associada ao risco respondida pelos homens.

Tabela 5. Perfil de Risco em função do gênero

\begin{tabular}{ccccc}
\hline Gênero & $\mathrm{N}$ & Média & Desvio padrão & $\begin{array}{c}\text { Erro padrão da } \\
\text { média }\end{array}$ \\
\hline Masculino & 163 & 6,96 & 3,163 &, 248
\end{tabular}

Tabela 6. Teste t-Student para amostras independentes

\begin{tabular}{lccccccc}
\hline & \multicolumn{8}{c}{ Teste t para igualdade de médias } \\
\cline { 2 - 7 } & $\mathrm{t}$ & gl & Sig. & $\begin{array}{c}\text { Diferença } \\
\text { média }\end{array}$ & $\begin{array}{c}\text { Erro padrão } \\
\text { da diferença }\end{array}$ & \multicolumn{2}{c}{$\begin{array}{c}\text { 95\% Intervalo de } \\
\text { confiança da diferença }\end{array}$} \\
\cline { 2 - 7 } & 2,590 & 305 &, 010 &, 888 &, 343 & Inferior & Superior \\
\hline$S^{2}$ iguais* & 2,610 & 305 &, 009 &, 888 &, 340 &, 213 & 1,562 \\
$S^{2}$ não iguais* & &
\end{tabular}

$(*)$ Teste de Levene para igualdade de variâncias $(F=2,566 ; p=0,110)$

Como $\mathrm{PR}_{\mathrm{M}} \neq \mathrm{PR}_{\mathrm{F}}(t \neq 0 ; p=0,010)$, rejeita-se $\mathrm{H}_{0,1}$ concluindo-se que o perfil de risco entre o gênero é diferente. Como a média do perfil de risco dos indivíduos do gênero masculino é maior que do gênero feminino, tem-se que os homens são mais propensos ao risco que as mulheres. 
Tabela 7 - Domínios e Gênero

\begin{tabular}{c|cc|cc}
\hline \multirow{2}{*}{ Questão } & \multicolumn{2}{|c|}{ Masculino } & \multicolumn{2}{c}{ Feminino } \\
\cline { 2 - 5 } & A & B & A & B \\
\hline Q1 & 61 & 102 & 52 & 92 \\
Q2 & 33 & 130 & 21 & 123 \\
Q3 & 60 & 103 & 38 & 106 \\
Q4 & 90 & 73 & 70 & 74 \\
Q5 & 51 & 112 & 40 & 104 \\
Q6 & 83 & 80 & 43 & 101 \\
Q7 & 47 & 116 & 33 & 111 \\
Q8 & 102 & 61 & 85 & 59 \\
Q9 & 105 & 58 & 106 & 38 \\
Q10 & 89 & 74 & 68 & 76 \\
Q11 & 103 & 60 & 84 & 60 \\
Q12 & 76 & 87 & 47 & 97 \\
Q13 & 81 & 82 & 67 & 77 \\
Q14 & 65 & 98 & 43 & 101 \\
Q15 & 88 & 75 & 73 & 71 \\
\hline
\end{tabular}

A Tabela 7 leva em consideração as 15 perguntas contidas no questionário, sendo que a opção " $\mathrm{A}$ " é do domínio da propensão ao risco enquanto a opção "B" é do domínio de aversão ao risco.

Teste de $\mathbf{H}_{0,2}$. A idade não é determinante do perfil de risco

Para testar a associação entre idade e perfil de risco foi utilizada a correlação por postos, de Spearmann. Como $\rho=-0,135(\rho \neq 0 ; \mathrm{p}=0,018)$, rejeita-se $\mathrm{H}_{0,2}$ concluindo-se que a idade impacta o perfil de risco dos indivíduos. Como o coeficiente é negativo depreende-se que à medida que a idade do indivíduo aumenta, diminui a propensão ao risco, (ou, analogamente, aumenta a aversão ao risco). Desta maneira pode-se afirmar que indivíduos mais jovens são mais propensos ao risco e, à medida que avançam na idade, tornam-se mais conservadores.

Teste de $\mathbf{H}_{0,3}$. A renda não é determinante do perfil de risco

No teste de associação entre renda e perfil de risco, $(\rho=-0,013 ; \mathrm{p}=0,831)$ não se rejeita $\mathrm{H}_{0,3}$, concluindo-se que a renda não é determinante do perfil de risco dos indivíduos.

\section{CONSIDERAÇÕES FINAIS}

O objetivo deste trabalho foi verificar se os aspectos socioeconômicos são determinantes no perfil de risco dos indivíduos estudados na Mesorregião Centro-Sul Paranaense. Das hipóteses estabelecidas, a primeira $\left(\mathrm{H}_{0,1}\right)$ foi rejeitada, pois se concluiu que o gênero é um fator determinante no perfil de risco dos indivíduos. A segunda hipótese $\left(\mathrm{H}_{0,2}\right)$ também foi rejeitada uma vez que a idade dos indivíduos apresentou-se significativamente associada ao perfil de risco. No entanto, com relação à renda $\left(\mathrm{H}_{0,3}\right)$ a hipótese nula não pode ser rejeitada, mantendo-se a suposição de que não é um fator determinante no perfil de risco dos indivíduos estudados.

Com a análise dos dados da pesquisa de campo espera-se trazer contribuições teóricas e práticas sobre a temática do estudo, onde o gênero e a idade são fatores que influenciam na 
tomada de decisão, desta maneira, os indivíduos do gênero feminino, como os de maior idade têm características mais conservadoras, enquanto que os estudantes do gênero masculino e mais jovens tendem à um perfil mais agressivo.

A partir das evidências encontradas neste trabalho pode-se expandir o estudo a uma outra parcela da população para aferir se os dados referentes aos investimentos do universo dos estudantes de Administração correspondem aos resultados obtidos, convergindo ao perfil da população. A partir do estabelecimento destes aspectos pode-se analisar os dados socioeconômicos dos investidores que atuam no mercado de ações, utilizando seus resultados na formulação de estratégias que considerem esses efeitos sobre o risco.

Como, originalmente, as finanças comportamentais buscaram compreender as relações do investidor com o mercado financeiro e os possíveis reflexos no processo decisório, pesquisas que identifiquem perfis de risco e padrões de comportamento proporcionam elementos de suporte para modelagem de risco e alocação de investimentos.

A pesquisa realizada não permite a generalização, cujas conclusões referem-se, em particular, à amostra do estudo. Outros estudos podem ser desenvolvidos envolvendo outros cursos na área das ciências sociais aplicadas, incluindo instituições públicas e privadas, com o objetivo de se comparar os resultados e evidências encontradas.

\section{REFERÊNCIAS}

Barberis, N., \& Thaler, R. (2003). Um levantamento das finanças comportamentais. Handbook of the Economics of Finance, Edited by G M Constantinides, M Harris and R Stulz, Elsevier B V.

Bernoulli, D. (1954). Specimen Theoriae Novae Sortis (St. Petersburg, 1738). English translation: Econometrica, p. 23-36.

Borsato, J. M. L., Pimenta, D. O., \& Ribeiro, K. C. S. (2009). Finanças Comportamentais: Um Estudo Descritivo sobre o Viés de Aversão à Perda no Processo Decisório. Anais... XII SemeAd Empreendedorismo e inovação. FAE-USP, São Paulo.

Cooper, R., \& Schindler, P. S. (2003). Métodos de pesquisa em administração. 7 ed. Porto Alegre: Bookman.

Fama, E. F. (1970). Efficient Capital Markets: A Review of Theory and Empirical Work. Journal of Finance. p. 383-417. May.

Fernandes, S. S., \& Ritta, C. O. (2012). Finanças comportamentais: um estudo com os alunos do curso de ciências contábeis de uma Universidade de Santa Catarina. Anais... III seminário de ciências sociais aplicadas, 3(3): Seminário de ciências sociais aplicadas.

Ferreira, V. R. M. (2008). Psicologia econômica: como o comportamento econômico influência nas nossas decisões. Rio de Janeiro: Elsevier.

Kahneman, D., \& Smith, V.; (2002). Fundamentos da Economia Comportamental e Experimental: informação avançada sobre o Prémio em Ciências Econômicas. (Foundations of Behavioral and Experimental Economics: Advanced information on 
the Prize in Economic Sciences) I05 Stockholm, Sweden.

Kahneman, D., \& Tversky, A. (1974). Judgment under Uncertainty: Heuristics and Biases. Science, New Series, 185(4157), pp. 1124-1131.

Kahneman, D., \& Tversky, A. (1991). Loss Aversion in Riskless Choice: A Reference Dependent Model Source: The Quarterly Journal of Economics, 106(4), pp. 1039-1061 Published by: The MIT Press.

Kahneman, D., \&Tversky, A. (1979). Prospect theory: an analysis of decision under risk. Econometrica, 47(2), p. 263-291.

Kahnernan, D., \&Taversky, A. (1977). Intuitive Prediction: Biases and Corrective Procedures, USMC Cybernetics Technology Office Defense Advanced Research Projects Agency Arlington. Virginia.

Kimura, H. (2003). Aspectos Comportamentais Associados às Reações do Mercado de Capitais. RAE-Eletrônica, 1(2), p. 2-14, jan./jun.

Leone, R. J. G., \&Alves, Willemberg H. L. (2011). Interpretação das exigências de prêmio por alunos de economia: um experimento de finanças comportamentais na UFPB. Revista de Contabilidade do Mestrado em Ciências Contábeis da UERJ, 16(1), art. 1, p. 2-18.

Markowitz, H. M. (1959). Portfolio Selection: Efficient Diversification of Investment. New Haven, Conn. (USA): Yale University Press.

Melo, C, L, L., \& Silva, C, A, T. (2010). Finanças comportamentais: um estudo da influência da faixa etária, gênero e ocupação na aversão à perda. $R C O$ - Revista de Contabilidade e Organizações - FEA-RP/USP, 4(8), p. 3-23, jan-abr.

Mendes, S, W., \&Abraham S, O, Y. (2009). Análise Empírica do Senso de Controle: Buscando Entender o Excesso de Confiança. RAC, Curitiba, 13(2), art. 5, p. 247-271, Abr./Jun.

Pereira, M. A., Vidal, T. L., Amorim, T. N., \& Fávero, L. P. L. (2010). Decision process based on personal finance books: is there any direction to take? Revista de Economia e Administração, 9(3), p. 407-425.

Pimenta, D. P., Borsato, J. M. L. S., \& Ribeiro, K. C. S. (2012). Um estudo sobre a influência das características sociodemográficas e do excesso de confiança nas decisões dos investidores, analistas e profissionais de investimento à luz das finanças comportamentais. Revista de Gestão, 19(2), p. 261-278.

Ritter, J, R. (2003). Behavioral finance Gainesville, FL 32611-7168, USA. Pacific Basin Finance Journal. 11, 429-437 University of Florida, PO. 
Rogers, P., Securato, J. R., \& Ribeiro, K. C. (2012). Finanças comportamentais no Brasil: Um Estudo Comparativo. In: Anais... $12^{\circ}$ Congresso USP Controladoria e Contabilidade. São Paulo.

Saurin, V., Varejão, J. M. J., Costa Jr., N. C. A., \& Prates, W. R. (2015). Estudo comparativo do viés do status quo e perfil de risco em tomadas de decisões por estudantes de cursos de pós-graduação. Revista de Administração Mackenzie, 16(5), p. 95-126.

Serpa, S. A. F., \& Silva, C. A. T. (2012). O efeito chamariz nas decisões de investimento. FACES Jornal Belo Horizonte. 11(1), p. 48-65 jan/mar.

Sharpe, W. F. (1964). A Theory of Market Equilibrium under Conditions of Risk. Journal of Finance. p. 425-442. Sep.

Shefrin, H., \& Statman, M. (1985). The Disposition to Sell Winners too Early and Ride Losers too Long: Theory and Evidence. The Journal of Finance, 40(3), p. 777-790. $<$ http://dx.doi.org/10.1111/j.1540-6261.1985. tb05002.x>.

Shiller, R, J. (2003). Markets Theory to Behavioral Finance. Journal of Economic Perspectives. 17(1), pp. 83-104.

Torralvo, C. F. (2010). Finanças comportamentais: uma aplicação da teoria do prospecto em alunos brasileiros de pós-graduação. Dissertação (Mestrado em Administração) Faculdade de Economia, Administração e Contabilidade, Universidade de São Paulo, São Paulo. Disponível em: <http://www.teses.usp.br/teses/disponiveis/12/12139/tde03112010-180040/>. Acesso em: 2017-05-17. 